\title{
Um Olhar Fenomenológico sobre as Crises Existenciais na Contemporaneidade
}

\author{
[A Phenomenological Outlook on the Existential Crisis in Contemporaneity]
}

\section{Rogério Holanda da Silva»; Ricardo Décio}

\begin{abstract}
Resumo: Este trabalho consiste em uma reflexão fenomenológica sobre a indigência do nosso tempo. Traz, na verdade, uma outra compreensão acerca dos malefícios que o atual momento tem causado ao ser humano ao imprimir um modelo de vida oferecido desde a modernidade e que implicou em uma série de inquietações, criando novas patologias. Trata-se de um movimento histórico, conhecido por Niilismo, que nos deu uma "nova morada", a qual, paradoxalmente, se mostra como não morada, um não-lugar, ou seja, um lugar estranho. Nesse lugar, residem desassossegos vigentes, como cansaço, stress, ansiedade, tédio, melancolia, depressão etc. Todavia, essas crises existenciais são interpretadas pelas ciências naturais como algo exclusivamente inerente ao corpo biológico dado. Essa interpretação é amplamente questionada aqui ao compreender que tais fenômenos só serão devidamente compreendidos mediante a analítica existencial do ser-aí humano, haja vista esse ente constituir-se como um ser-no-mundo que tem como horizonte a temporalidade.
\end{abstract}

Palavras-chave: Niilismo. Stress. Ansiedade. Depressão. Ser-aí.

\begin{abstract}
This article consists of a phenomenological refection about the indigence of our time. It discusses another understanding of the harm that the current moment has been causing to the human being, when instilling a life model offered since modernity, that involves several concerns, creating new pathologies. It is a historical movement, known as Nihilism, that gave us a "new dwelling place", one that, paradoxically, shows itself as a non-dwelling-place, a non-place, namely, a strange place. Existing restlessness such as tiredness, stress, anxiety, boredom, melancholy, depression, etc., are present at this place. However, these existencial crisis are interpreted by the natural sciences as something that is solely inherent to the biological body. This interpretation is widely questioned here, since we understand that these phenomena will only be properly understood through the existential analytic of the human existence, since this entity is constituted as a being which temporality is the horizon.
\end{abstract}

Keywords: Nihilism. Stress. Anxiety. Depression. Existence.

\footnotetext{
${ }^{*}$ Atuou como professor do departamento de Filosofia da Universidade do Estado do Rio Grande do Norte - DFI/UERN. Formado em Filosofia, Geografia e Mestre em Ciências Sociais e Humanas. Pesquisador na área da filosofia contemporânea com ênfase na fenomenologia e existencialismo. E-mail: holandarogerio@hotmail.com. ORCID: https://orcid.org/0000-0002- 8253-4967.

${ }^{* *}$ Bacharel em Psicologia pela Universidade Potiguar - UNP. Integrante do Núcleo de Estudos, Ensino e Investigações em Filosofia - NEFIL/UERN. Pesquisador da abordagem Daseinsanálise: de base hermenêutica, fenomenológica e existencial. E-mail: ricardo.decio01@gmail.com. ORCID: https://orcid.org/0000-0002-9426-348X.
} 


\section{Introdução}

À luz do pensamento ontológico e fenomenológico do filósofo alemão Martin Heidegger (1889-1976), dialogando com Nietzsche, Byung-Chul Han, Cioran e outros autores, buscamos compreender as crises existenciais ou o malestar da contemporaneidade, constituído por alguns fenômenos, entre eles: cansaço, stress, burnout, ansiedade, depressão, vazio existencial. Nosso desejo é ir além da explicação superficial das ciências naturais positivas (neurológicas), uma vez que, no âmbito dessas ciências, o ser humano é visto apenas como uma composição químico-física, isto é, uma substância, um ente vivo simplesmente dado e, por isso, detentor de determinadas propriedades inatas biológicas. Conforme essas ciências, acredita-se que uma simples disfunção hormonal ou uma "má" formação neurológica seria parte das causas desses fenômenos que levariam ao sofrimento humano.

Essa é uma compreensão cogitada pelo pensamento moderno e se constitui um entendimento superficial, pois perde de vista o sentido existencial do ser humano. Trata-se de uma visão que não concebe o mesmo a partir de sua condição fática, ou seja, do ser-aí
(Dasein) $)^{1}$. Isto é, um ente jogado no mundo totalmente aberto para o poderser mediante o tempo ${ }^{2}$ no qual se encontra imerso. De acordo com essa visão moderna fisiológica, o ser humano é pensado a-historicamente e atemporalmente, por consequência, sua correlação com o mundo vivido é completamente esquecida, por pensar o ser humano como um sujeito (substância) cerebral, separado do mundo.

Diante do exposto, é necessário fazermos um exercício de interpretação de caráter fenomenológico atentando para aquilo que se mostra, em nosso tempo, contido nas vivências intencionais de cada afinação enquanto experiência. Tais fenômenos, ou tonalidades afetivas, não são, em suma, uma "coisa". Tampouco podemos dizer suas "causas" do ponto de vista químicofísico, justamente pelo fato de a existência do ser humano não ter um ponto de início nem de chegada, nem um processo a ser racionalmente organizado, mas sim travessia, afetação.

No entanto, é com base na analítica do ser-aí, isto é, do ente que atravessa a facticidade de tudo aquilo que é, de tudo que é dado onticamente, e no diálogo com outros autores é que buscamos entender os fenômenos que veem conduzindo o ser humano às crises exis-

\footnotetext{
${ }^{1}$ Nesse artigo, o termo ser-aí, ou presença, corresponde à tradução do termo alemão Dasein, isto é, a essência do ser humano numa perspectiva existencial. Nessa perspectiva, o ser-aí não é simplesmente um ente que se encontra entre outros entes. Ele se distingue dos demais entes pelo seu privilégio ôntico, pelo fato "de, em seu ser, isto é, sendo, estar em jogo seu próprio ser" (HEIDEGGER, 2015, p. 48).

${ }^{2} \mathrm{O}$ tempo aqui não deve ser interpretado num sentido cronológico (hora, dia, semana, mês ou ano), mas como a própria temporalidade, isto é, o horizonte por onde o ser-aí estrai sua existência, ou seja, sua compreensão de ser.
} 
tenciais. Acreditamos que tais crises decorrem, de certa forma, do "como", ou melhor, do modo de ser existencial do ser humano proporcionado por um tempo que lhe é estranho. Este é um tempo indigente, um tempo que não é propício para a vida confortável, no caso, o tempo atual, o grande causador das crises existenciais na contemporaneidade.

\section{A indigência do nosso tempo: o Nii- lismo}

O ser humano, na perspectiva heideggeriana, só será devidamente compreendido se for analisado mediante o tempo ou a temporalidade em que se encontra inserido, haja vista este tempo se incumbir de fundamentar seu modo de ser. Como ente temporal o ser humano, enquanto ser-aí, é aberto para o ser, ou seja, "em seu ser, isto é, sendo, este ente se relaciona com seu próprio ser" (HEIDEGGER, 2015, p, 85). Porém, sua relação direta com o seu próprio ser, mostra que este ente não é em si mesmo, mas sempre se define como um vir-a-ser. Como um vir-a-ser ele se torna apropriador das condições imputadas pelo tempo, mesmo aquelas que o aflige e traz sofrimento. Uma dessas condições é o Niilismo?, compreendido aqui como uma indigência do nosso tempo. Na ótica da fenomenologia e hermenêutica heideggeriana, é o responsável pelas perturbações e patologias para a vida no seu contorno geral e em especial pela retirada do sossego do ser humano nesse mundo dito pósmoderno.

Fernando Pessoa (1999) faz uma descrição, de certa forma, trágica da modernidade. Ele fala a respeito da indigência em que nos encontramos em meio ao vazio deixado pelo Niilismo, que nos colocou na berlinda, na estrangeridade, provindo da falta de sentido e da sedimentação do mundo técnicocientífico. O poeta nos mostra como ficamos afetados em meio à era da funcionalidade maquinal, na qual se estabeleceu uma hiperexcitação, corroendo as mais densas experiências e estruturas ontológicas, sedimentando uma péssima morada para nós habitarmos. Essa modernidade configurou um mundo estranho ao nosso ser, de modo que "nascemos já em plena angústia metafisica, em plena angústia moral, em pleno desassossego político" (PESSOA, 1999, p. 187).

A partir da compreensão do Niilismo, como a perda de grande parte dos valores supremos e essenciais à vida humana, é que reivindicamos como responsável pelas crises existenciais humanas que vem definhando o ser humano na contemporaneidade. Por-

\footnotetext{
"Traduzido literalmente, niilismo significa algo assim como um nadismo, uma fome de nada, uma redução de tudo a nada" (CASANOVA, 2013, p. 175).
} 
tanto, o Niilismo foi e "é" o acontecimento apropriador que põe atmosferas, abrindo o espaço para uma nova forma de existir do ser humano, onde se mostra a presença da experiência do nada. Nesse sentido, o Niilismo, enquanto movimento instaurador de quebra de valores e da constituição de novos,

\begin{abstract}
Aponta diretamente para a suspensão inicial de toda transcendência, de toda imanência, de toda causa, de toda finalidade, de todo ser, de toda unidade, de toda identidade, de toda substância e de todo fundamento da totalidade. (CASANOVA, 2013, p. 194).
\end{abstract}

De outro modo, pode se dizer que o advento do Niilismo trouxe a eliminação de categorias metafísicas, como por exemplo: a crença na verdade absoluta, que sempre sustentou nossa tradição. "A existência do homem ocidental como um todo foi, desde o princípio, erigida a partir de uma orientação pelo mundo verdadeiro, pela identidade, pela essência, pela forma, pelo repouso, pelo eterno." (CASANOVA, 2013, p. 190). Isso significa que se não podemos operar mais com tais categorias, a existência se torna um problema, mostrando-se completamente sem sentido, transitória.

A metafísica, segundo Casanova (2017), parafraseando o poeta alemão Novalis, é uma nostalgia da terra natal, uma vontade de estar por toda parte em casa. No desaparecimento dela, o homem moderno se vê desatado de seu sol. Sem pátria não existe mais "uma" direção universal, mas "muitas" direções. No limite, essas direções são superficiais, assim todos os lados apontam para uma desconexão, surgindo um grande enfado e um caos perpétuo toma conta da convivência. Como bálsamo para isso tudo ocorre a imersão em modos automáticos, técnicos, destituídos de significados.

Nessa deterioração, o ser humano contemporâneo se mostra suspenso em uma precariedade ontológica (a perda do ser) que alterou grandemente a percepção no mundo pelos determinados modos de proceder, decorrentes do mar de possibilidades que viabilizam certos sofrimentos e tonalidades afetivas. Ora, se toda essencialidade se volatilizou, o que está em vigência em todo o mundo é o "devir", a mutabilidade, a pluralidade. Desse modo, o ser humano se reduz à mera constituição das relações, de modo que "sua identidade, por fim, não é se não uma ilusão, o resultado de um processo historicamente constituído e sedimentado de simplificação. " (CASANOVA, 2013, p. 194), o que não diz respeito ao seu ser mais ontológico.

A secularização e o mundo da técnica moderna alteraram, portanto, nossa forma de pensar e se comportar, de ser e estar no mundo, de modo que nossa imaginação e fantasia esvaneceram por conta de uma realidade efetiva que se 
tornou soberana.Como disse Nietzsche (2012, p. 149), “[...] a iluminação e o colorido das coisas mudaram! Já não compreendemos totalmente como os antigos experimentavam o que era mais frequente e imediato - o dia e a vigília." Passamos pela vida como estrangeiros, sem nortes, em uma corrida sem início e nem chegada, ou seja, sem nos preocuparmos, necessariamente, com nosso modo de ser nesse mundo. Cada vez mais nos aproximamos e nos relacionamos com os entes a nossa volta, ao mesmo instante em que nos distanciamos de nós mesmos. Esse distanciamento levou a deformação da nossa própria imagem e, como consequência, a criação de uma nova criatura.

Uma das principais características do atual momento é a velocidade das transformações sobre a vida das pessoas. A frenesi dessa pressa por mudança, excluem-se diretamente as experiências mais densas e ontológicas 4 . Comprometendo a qualidade de vida do indivíduo ao conduzir-lhe ao desassossego. Nessa perspectiva, o ser humano não se reconhece mais diante si, e como disse Nietzsche (2012, p. 150): "Correm como ébrios pela vida e de quando em quando caem por uma escada abaixo." Isto é, imersos nessa vida descompassada, os seres humanos não têm uma visão clara do que estão vivendo. O sentido pelo prazer de viver, cada vez mais, se integra a busca do novo, do corriqueiro, do ilusório, ou seja, das imputações oferecias por esse tempo.

Essa compreensão mostra o quão a embriaguez moderna tem aniquilado a vida nos mais variados sentidos, levando-nos a uma desconexão com a própria existência mais autêntica. Sendo que a principal causa é, justamente, o excesso de solicitações, isto é, a quantidade de tarefas e objetivos a serem realizadas. Essa é a característica de um modo de ser não vivenciado em outras épocas.

Qual a importância, então, de compreendermos nosso tempo? Olhando atentos para o envio do tempo, despertamos para aquilo que é próprio dele: a indigência; os discursos de verdade e normatividade que o perpassam; a predominância de certos dogmas identitários vigentes; o vigorar da funcionalidade; o modelo mecanicista-biológico; o pensamento calculador, quantificador e dominador da técnica; a opressão de certas sistematizações. Tudo isso são condicionantes da vida humana criada pelo nosso tempo. De acordo com Heidegger (2008, p. 02): “[...] a vida humana é orientada, em sua tarefa mais cotidiana, por via do tempo. A vida humana encerra em si mesma numa regulamentação temporal." Nesse sentido, o tempo deve ser o horizonte primordial para se compreender os fenômenos que veem acometendo a vida na contempo-

\footnotetext{
${ }^{4}$ Experiências que falam de sua essência, isto é, de sua existência.
} 
raneidade.

Em virtude dessa condição de ser temporal, a contemplação, a tranquilidade e o sossego que o ser humano tinha por um período conhecido como pré-moderno, esvaiu-se por conta da fragmentação das particularidades possibilitadas pelo movimento científico operacional da modernidade, "[...] transformando o acontecimento psicológico no que vou chamar uma experiência ontológica: o encontro com a condição humana no seu caráter temporal." (BORGES-DUARTE, 2018, p. 215). Entendemos, pois, que, em se tratando dos fenômenos psicopatológicos, foi o tempo que alterou nosso ser-corporal, uma vez que nosso corpo é o primeiro a sentir qualquer alteração, por estar sempre em jogo.

Essa condição imposta pela modernidade nos deixou amplamente limitados e entregues às condições deliberadas pelas nossas relações diretas com os entes intramundanos 5 , tentando buscar um conforto e alívio para uma melhor existência, mas de todo modo frágil, superficial, efêmero, não abarcando a totalidade existencial. Por isso, ficamos suscetíveis a tais situações que possibilitam a eclosão de certos fenômenos nocivos à saúde, tais como: cansaço, stress, ansiedade e outros. De acordo com Borges-Duarte (2018, p. 233): “[...] em todos estes fenômenos assistimos ao paradoxo do tempo vivido, a presença da inquietude na calma e da calma da inquietude." Portanto, são fenômenos típicos da sociedade atual.

\section{Cansaço, Stress, Ansiedade: desas- sossegos do ser-com}

Tudo que se passa no onde vivemos é em nós que se passa. Tudo que cessa no que vemos é em nós que cessa (PESSOA,

$$
\text { 2011, p. 36). }
$$

A vida moderna nos trouxe um ritmo frenético de atuação no mundo, trazendo excessivas solicitações, na maioria das vezes desnecessárias para o exercício do bem-estar do ser humano. Pressionados pelos modos de ser dos quais não damos conta, sobrecarregamos nossa existência de coisas fúteis e degradantes.

Enredada na perspectiva da positividade e na ideia de progresso, a sociedade contemporânea presencia o ser humano cansado e exausto pela exacerbação de tarefas à serem cumpridas no dia-dia, de tal forma que nos encontramos, na maioria das vezes, extenuados e fadados a perecer prematuramente. Como disse Borges-Duarte (2010, p. 02): “[...] na modernidade a vida mesma viu-se capturada no interior de uma espiral de consequências incontroláveis e imprevisíveis."

\footnotetext{
${ }^{5}$ Entes intramundanos são os entes simplesmente dados no mundo, como cadeira, mesa, porta, etc. São os entes que, na manualidade, veem ao encontro do ser humano.
} 
É nesse ensejo que o filósofo ByungChull Han (2017), em seu ensaio "Sociedade do cansaço", mostra minuciosamente o nosso tempo. Sua ideia base é que vivemos em uma sociedade constituída por uma positividade muito exacerbada, que traz em si o ideal de sucesso ou realização pessoal ao extremo. Nessa perspectiva, tornamonos patrões de nós mesmos, mesmo não sendo patrões. No entanto, o autor está mostrando que o modo de exploração ganhou uma nova forma, a saber, da auto-exploração, isto é, o indivíduo, na busca de atingir certos padrões impostos, se sobrecarrega de atividades e desejos que não são próprios dele, mas de um modo de ser típico da sociedade moderna.

Ademais, ao sermos compelidos a nos moldarmos constantemente, não temos espaço nem tempo para colocar a posição antagônica, isto é, a negatividade da vida como o lado oposto à exacerbada positividade. Nesse modo de vida, o negativo é inaceitável, porém, a sua não aceitação torna a vida um preço muito alto. Não pensamos esse antagonismo. Passamos, então, a ser uma sociedade extenuante (exaustiva, fadigosa, enfadonha), por ser positiva demais, manifestando uma posição não-dialética da vida, porque é uma sociedade que precisa do positivo sem que o negativo se apresente.

Segundo Han (2017), a imersão desenfreada nessa positividade se mostra extremamente cansativa, levando ao esgotamento social pelas performances em grande escala, manifestando o adoecimento existencial em massa que faz romper a casca dos sentidos cotidianos que nos tranquilizam dando lugar a um abatimento que corrói brutalmente todo nosso ser. Por consequência, somos requisitados e interpelados por uma avalanche de solicitações (progresso, status, poder, riqueza material, estudos, trabalhos etc.) que nos desnorteiam. Por serem muitas solicitações, não conseguimos atender a todas, o que imediatamente nos causa certa inquietação e somos diretamente afetados, chegando ao stress, ansiedade, depressão, suicídio e outras patologias.

Nos “Seminários de Zollikon" (2017), o filósofo alemão Martin Heidegger nos mostra o fenômeno do stress saindo da visão químico-física da ciência neurológica. Ele aponta para nossa relação-com o ser-no-mundo (Dasein) marcada por uma aceleração incessante do mundo da técnica, que nos convida a participar ininterruptamente de tarefas cada vez mais exigentes em nossa convivência. São solicitações excessivas que nos interpelam abruptamente, conduzindonos a estados patológicos quando não conseguimos responder a determinados chamados do mundo que veem ao nosso encontro.

Estresse significa solicitação. No caso solicitação excessiva. Em geral, a solicitação exige em cada caso um correspon- 
der de alguma forma. A esse corresponder pertencem também, como privações, o não corresponder e o não podercorresponder 2017, p. 154).

Trata-se, portanto, de uma condição muito difícil para o ser humano, uma vez que temos de corresponder, cada vez mais, àquilo que está posto, isto é, solicitado pelo mundo, respostando, a cada instante, na nossa presença, aos chamados da vida para uma atuação nesse mundo. Mas, o que vem acontecendo com o nosso tempo, além do lançamento de miríade de chamados, como bombardeio ininterrupto de obrigações que nos interpelam fortemente (família, faculdade, filhos, trabalho, amigos, etc.), é a internet. Esta, com seus grupos sociais diversos, aumentou exponencialmente ainda mais as solicitações: diminuindo o tempo, aumentando a pressa, aproximando e distanciando as pessoas ao mesmo instante. Um verdadeiro paradoxo.

É nesse prisma que a responsabilidade, isto é, a nossa forma de respostar aquilo que está posto advinda dos chamados da existência, fica completamente enfraquecida, uma vez que são muitos chamados no mesmo instante, acontecendo, com isso, o stress como solicitação excessiva do ser, a qual nos leva a uma carência de respostas pelo excesso, se configurando como uma verdadeira opressão.Todavia, é importante deixar claro que o problema não é ser solicitado, mas o excesso de solicitações, no qual leva a emancipação dos fenômenos como stress e ansiedade, burnout, entre outros.

Por sua vez, o ser humano, como ente que se constitui mediante a existência, sempre está aberto para as solicitações necessárias. A falta delas leva-nos a desopressão que é, na verdade, uma forma de desassossego oposto ao da opressão. E como isso acontece? Quando não há o que corresponder, isto é, quando não somos mais solicitados. Quando paramos, sem alguma tarefa obrigatória, esvaziamo-nos da interpelação e, por um momento, ficamos em outra forma de chamado: o vazio. O aposentado mostra bem que a interpelação não desaparece quando estamos livres das obrigações profissionais, “[...] ela permanece justamente, na verdade, como obrigação vazia e não preenchida, e como tal torna-se uma solicitação incomum e, pois, excessiva 'depressão da desopressão.’” (HEIDEGGER, 2017, p. 156).

Borges-Duarte (2018), em seu artigo "Sossego e desassossego: o paradoxo do tempo vivido", mostra-nos que essa relação existencial marcada fortemente pela efemeridade está perpassada pela ambiguidade de ser e não ser ao mesmo tempo senhor de si nesse exercício. Isso causa um fechamento das possibilidades, aparecendo diversas modificações como a ansiedade, advinda do stress oriundo do excesso de solicita- 
ções, tanto na tensão como no contrário. Nessa perspectiva, o stress é um fenômeno que procede do mundo cotidiano, ou seja, da lida do ser humano com os seus afazeres, na maioria das vezes, em excesso. É, portanto, um fenômeno agravado pelo mundo contemporâneo onde exige que tudo seja muito rápido e prático, porém essa rapidez e essa praticidade, muitas vezes, vem em desacordo e com certa nocividade, pelo modo ou funcionalidade das exigências, seja ela profissional ou pessoal, chegando a sacrificar a vida.

Portanto, vivemos em uma temporalidade corrosiva, que desconexa o ser humano de sua realidade mais próspera e mais equilibrada. Essa desconexão é requisitada pelo "tempo atomizado" que, com sua dinâmica, alterou nosso "aí", levando-nos ao comportamento estressado em todo convívio social e individual. Nesse rol, surgem, gradativamente, os sinais de definhamento do indivíduo. Primeiramente,

Começa por ser o corpo a manifestar o cansaço, a exaustão; a agitação, o frenesim; as palpitações, a tensão alta. Juntase-lhe a ansiedade, a falta de um sono descansado, a perda da memória, a incapacidade de concentração. O rendimento mental começa a claudicar, o comportamento descontrola-se, a função deixa de ser cumprida como devia. Ao esgotamento, junta-se o sentimento de culpa, a vergonha pela incapacidade de corresponder ao seu papel, a depressão. Aos aspectos orgânicos e psicológicos do stress juntam-se o seu alcance sóciocultural, numa civilização em que o tempo é ingrediente de um movimento de ritmo acelerado e de pausas estratégicas, não sendo tolerados os fracassados. É um movimento epocal. $\mathrm{Na}$ análise fenomenológica, o stress aparece como o fenômeno que expressa esta aceleração de um tempo sem tempo para hiatos e demoras, um contínuo de momentos fragmentários, de urgências diferentes sucedendo-se ininterruptamente sem estarem ligadas entre si (BORGES-DUARTE, 2018, p. 221).

Contudo, isso só é possível mediante o modo de ser na existência, algo caríssimo ao ser humano, justamente por sobrepô-lo no confronto diário ao ter que responder às solicitações. Logo, a existência é o nosso ser mais ontológico que tem o caráter de abertura [ekstática] para compreensão do ser em geral, o que permite o ser humano distinguir-se dos outros entes ao ponto de se constatar que "a pessoa - o ser humano - não é um ser substancial, nos moldes de uma coisa" (HEIDEGGER, 2015, p, 92). É por essa condição, portanto, 
que ficamos vulneráveis ao desassossego, pela insuficiência de nossas respostas, ou por aquilo que esperam de nós. Situação que nos leva à carência de requisição que se alastra como veneno na corporeidade do ser-aí humano. $\mathrm{Na}$ ânsia, "antecipamos o porvir", adiantando eventos, acontecimentos futuros que podem vir ou não, imaginando e supondo sobre o que vai acontecer e como será esse futuro que se faz presente, propiciado pela ansiedade, corroendo todo o nosso ser.

Além do stress, somos acometidos também pela ansiedade, que se mostra, segundo Casanova (2017), pelo próprio ser-no-mundo, onde nos encontramos em relação com os outros (ser-com) e com as coisas (ser-em), nas experiências mundanas que corporamos. Perpassados pela imediatidade, pela competitividade, pelo peso que a sociedade impõe de sermos sempre vencedores, pela pressão das obrigações e pela frustação de "não respostar no presente" a solicitação excessiva, gerando, assim, o stress que desemboca na ansiedade. Essa condição leva nosso corpo imediatamente a ser o primeiro a sentir, alterando nosso comportamento. Isso porque o corpo é um fenômeno que se constitui a partir de nosso ser-aí.

Ser um ser-aí não é ser um ponto do todo, mas ser a partir do predomínio primário do aí enquanto espaço existencial significativo articulado por sen- tido. Em outras palavras: enquanto espaço marcado pela abertura de uma totalidade conformativa, com os seus lugares, regiões, proximidades e distancias surgindo exatamente dessa abertura. (CASANOVA, 2017, p. 128).

Quando somos afetados ficamos ansiosos por querer a todo custo uma resposta imediata sobre o que está acontecendo conosco. Com isso, imergimos em uma paranoia em achar que tal ansiedade é unicamente um problema do corpo fisiológico, uma doença que subsiste por si no âmbito psíquico cerebral, como atos isolados ou emoções da consciência e que podem ser curadas com medicamentos. Contudo, não é bem assim, "[...] o anseio: quem anseia é o Dasein. O ansioso é o próprio ser-no-mundo" (HEIDEGGER, 2017, p. 181). Dito de outra forma, a ansiedade decorre do modo de ser existencial do ser humano, haja vista ser uma correspondência de ser-no-mundo. Ser-estaransioso é, portanto, uma condição preconizada pelo seu "aí", isto é, pelo seu ser fora de si, ou seja, o ser-aí (o Dasein).

Outrossim, a ansiedade, como outros fenômenos (vontade, querer, tender, desejar, etc.), está diretamente ligada à estrutura ser-no-mundo, na relação do campo correlativo intencional, como frisou Husserl (2014). Destarte, querer "algo", desejar "algo", está ansioso por "algo", já se mostra imediata- 
mente à minha frente como uma condição decorrente do ser-no-mundo, isto é, do ente que está fora de si mesmo. Esse fora, enquanto condição ontológica do ser humano, é um correlato da abertura do mesmo para-com-o-mundo e todos os entes que sempre já se encontram juntos. Portanto, essa forma de ser é fundamento de significação para fenômenos como: querer "algo", buscar "algo", desejar "algo". Porém, esses fenômenos não podem ser pensados como "pulsões", tal como apontou Freud em sua teoria da libido, ou seja,

Não se trata de um processo psíquico indefinido, de um "mecanismo de pulsão mitológico" (Freud), que me impulsiona, mas sim de algo determinado em nossa existência, isto é, de um poder-serno-mundo determinado, pelo qual nós decidimos, no sentido de nos termos aberto para isto. Nós temos de concordar com este estar aberto, temos de aceitá-lo (HEIDEGGER, 2017, p. 180).

Essa compreensão sobre a ansiedade nos leva a olhar para a facticidade em que estamos imersos em nossa convivência. Podemos ver, então, a correria que se transformou nosso ser e estar no mundo contemporâneo: as obrigações; solicitações excessivas; falta de correspondência como carência de requisição; e a busca de objetivos que se mostram, na maioria das vezes, maléficos. Essa dinâmica nos faz definhar e nos dobrarmos à ansiedade por anteciparmos muitas correspondências que se encontram no horizonte mundano.

Desse modo, como entes abertos [eksistere], precisamos entender o nosso tempo para poder compreender os modos de nosso ser nesse mundo, o qual nos lega uma gama de solicitações e embargos que alterou nossa relação mais própria. Enquanto abertura, podemos ser, dessa ou de outra maneira, estando sempre susceptíveis às transformações do mundo e ao peso de suas significações sedimentadas como correlato intencional do existir.

Portanto, a vida nessa "correria" cotidiana, típica deste tempo em que "vivemos", encontra-se carregada por um certo vazio que jamais será preenchido, justamente porque há uma fragmentação nos objetivos e sensações aspiradas pelos indivíduos. Como consequência, surgem: o tédio, a melancolia e a depressão, isto é, as tonalidades afetivas que afetam diretamente a saúde e o bem-estar do ser humano nos mais diversos modos. 


\section{Tonalidades afetivas tedium vitae, depressão, melancolia}

Elas são jeitos do ser-aí, e, com isto, do ser fora. Uma tonalidade afetiva é um jeito, não apenas uma forma ou um padrão modal, mas um jeito no sentido de uma

melodia, que não paira sobre a assim chamada presença subsistente própria do homem, mas que fornece para este ser o tom, ou seja, que afina e determina o modo e o como de seu ser. (HEIDEGGER, 2015, p. 88).

Em "Ser e Tempo", o filosofo alemão Martin Heidegger (2015) abriu uma grande chave de compreensão sobre o ser humano e sua condição existencial no século $\mathrm{XX}$, com aquilo que ele chamou de "tonalidades afetivas fundamentais". Sua interpretação se contrapõe às determinações metafisicas vigentes, até então, como disfunções da "[...] psique, mente, cérebro, consciência, subjetividade, e do corpo biológico". (HEIDEGGER, 2015, p. 88). Contrariamente, tais tonalidades são atmosferas afinadoras que se mostram em certos fenômenos, como tédio, melancolia, medo, temor, tremor, ansiedade, depressão, angustia, etc. Essas disposições advêm do embate relacional de afetação que o ser-no-mundo absorve em sua lida existencial, haja vista o ser humano ser um ente aberto para o ser. Isso implica dizer que uma existência não se constitui a partir de uma natureza determinada.

Nesse horizonte, no livro "Os concei- tos fundamentais da metafísica: mundo - finitude - solidão", Heidegger (2015) atenta para "despertar" uma atmosfera que apropria nosso tempo e nos faz entender o "tédio-profundo" e suas variações como a "tonalidade afetiva fundamental do nosso tempo". O filósofo enfatiza não um diagnóstico médico, nem uma coisa simplesmente dada no "homem" como uma propriedade que constatasse por mero arbítrio, onde se porta ou não. Na verdade, essa atmosfera já está sempre "aí", como um envio histórico que se abate sobre o ser humano. Aparentemente adormecida, apesar de velada pelas ocupações, se encontra em toda parte e em parte alguma. Desse modo, para o filósofo:

As tonalidades afetivas não são manifestações paralelas, mas justamente o que determina desde o princípio a convivência. Tudo se dá como se uma tonalidade afetiva sempre estivesse aí, como uma atmosfera, na qual sempre e a cada vez imergimos e desde a qual, então, seriamos transpassados por uma afinação (HEIDEGGER, 2015, p. 87-88).

Segundo Casanova (2015), o que o filósofo tem em mente com a palavra alemã para tonalidade afetiva [Stimmung] significa "astral". Trata-se daquilo que produz um ânimo em um ambiente, colocando todos em certa sinto- 
nia, como uma melodia que ressoa a todos nós no mundo. Essa tonalidade se encontra já no "aí" como possibilidade da nossa lida cotidiana, bem como em nossos projetos de fuga do tédio. Não deve, entretanto, ser confundida com um estado de humor, pois, desse modo, se refere sempre a um matiz subjetivista. O foco é atentar para a totalidade do acontecimento que contagia a todos nós na contemporaneidade, a saber, $o$ tédio-profundo como via régia de uma experiência ontológica.

Esse tédio-profundo é, para Heidegger, a depressão, sendo considerada, de forma unânime, a doença "do século" e não do homem. Essa afirmação está corretíssima. O que não está apropriado é tratá-la tomando como fundamento a forma neurobiológica ou mental, pois, onde topologicamente, se encontra a atmosfera, o "astral"? Nos nervos, no cérebro, nos neurônios? Pergunta indecifrável. Mas, a resposta é esta: em nenhuma parte das massas anatômicas. Por quê? Por justamente se tratar de um modo de ser. E esse "estado" perpassa todos os lugares, não só dentro de nós. Logo, "[...] não é um fenômeno psicológico, mas antes, o existencial a partir do qual é possível qualquer variação psíquica dos afetos ou 'estados de ânimo'” (SÁ, 2017, p. 56).

Essa nomeação do tédio é uma forma de englobar todas as outras modificações dessa afinação: tristeza, melancolia, depressão e tédio profundo. Constitui-se um astral que temporaliza nossa abertura, descerrando mundo, ressoando nos espaços de acontecimentos de acordo com a quebra de sentidos de nossa relação, avisando-nos sobre nossa negatividade. Dito de outro modo, a nadidade, nossa forma existencial mais própria de ser, revela a indeterminação ontológica, convidandonos, assim, para uma volta sobre nossa existência quando permanecemos em sua presença afetiva.

\begin{abstract}
No tédio verdadeiro não se sente tédio apenas por algo determinado, mas sente-se tédio em geral. Isto é: tudo nos interpela igualmente pouco. No tédio [Langeweile], que quer dizer tempo longo, o tempo desempenha um papel como a palavra diz. Não há mais futuro ou passado ou presente. No tédio acontece a solicitação não excessiva do ser (HEIDEGGER, 2017, p. 208).
\end{abstract}

Sobre essa afinação das tonalidades, a psiquiatria e a psicologia positivista, ancoradas no discurso da neurociência, tentam delegar a tarefa de existir para os neurotransmissores, para uma subjetividade cerebral encapsulada. A existência humana e sua abertura de sentido são muito maiores que a mera anatomia biológica que tenta objetivar o ser do homem. Todavia, "[...] as teorias psicológicas surgem sob a pressão da tradição, porque a tradição nada conhece 
além do caráter do ser da substancialidade e da objetivação e da coisificação." (HEIDEGGER, 2017. p. 214). Portanto, essa tradição tem dificultado o avanço da ciência, não permitindo conhecer os fenômenos de modo mais essencial.

Por via da fenomenologia percebese que, o tédio, a partir da experiência do indivíduo neste mundo, constitui-se como a atmosfera morta da falta de vida dos apartamentos, advinda da pobreza das experiências, do vazio do nosso tempo, da laboriosidade incessante. Segundo Nietzsche (2005), isso foi possibilitado pela razão instrumental, que tem como paradigma a vita activa do homem, transformando-o em animal laborans. Através dessa concepção, tanto o trabalho como o repouso passam a uma espécie debitária desse esquema, acabando com a visão contemplativa de admiração, do espanto e da demora, por sempre se estar a fazer algo, como que impelindo o tédio de se mostrar.

O que é o tédio? É o hábito do trabalho mesmo, que se faz valer mais forte quanto mais estivermos habituados a trabalhar, e talvez quanto mais tivermos sofrido necessidades. Para escapar ao tédio, ou o homem trabalha além da medida de suas necessidades normais ou inventa o jogo, isto é, o trabalho que não deve satisfazer nenhuma outra necessidade a não ser a de trabalho. (NIETZSCHE, 2005, p.
258).

Assim como as compreensões de Nietzsche e Heidegger, Machado de Assis (2001), em seu conto "Viver", mostra, de forma precisa, o advento dessa tonalidade afetiva possibilitada pela modernidade. Enfatiza o peso do profundo fastio que a sociedade do século XIX estava passando através do diálogo dos personagens míticos Prometeu e Ahasverus, este último um judeu errante que ficou condenado a andar para sempre até o fim dos tempos por ter empurrado Cristo no dia de sua crucificação e não ter tido piedade dele. $\mathrm{O}$ escritor analisa a pressa e o fastio do tédio de acordo com o diálogo. Segue um trecho:

Prometeu. - Vai, vai. Que pressa tens em acabar os teus dias?

Ahasverus. - A pressa de um homem que tem vivido milheiros de anos. Sim, milheiros de anos. Homens que apenas respiraram por dezenas deles, inventaram um sentimento de enfado, tedium vitae, que eles nunca puderam conhecer, ao menos em toda a sua implacável e vasta realidade, porque é preciso haver calcado, como $\mathrm{eu}$, todas as gerações e todas as ruinas, para experimentar esse profundo fastio da existência. (ASSIS, 2001, p. 117). 
A descrição acima mostra o peso do tédio de suportar seu ter de ser que, segundo Heidegger (2015), constitui a "serenidade vazia" que o interpela, chegando na estagnação monótona da vida. É pela "disposição da tonalidade afetiva" que o ser-aí se encontra. Com ela, nossos campos de visão e percepção se modificam, por isso dizemos: "o mundo está triste, a praia tediosa, a casa sem brilho". Portanto, uma coisa só pode ser entediante junto a nós porque a atmosfera já gira em meio e em torno de todo o campo existencial. Como pode se dar isto? Através de dois fenômenos: no comum "aborrecerse", que propicia uma situação vivida determinada, sem sua plena realização (ex: uma espera do trem em uma estação que se atrasa) gerando a frustação, caracterizando o "ser-entediado por algo"; e no estado doentio do tédioprofundo, que aparece como uma inibição da ação.

Então, se o tédio é algo contra o que sempre lutamos, aonde ele se mostra? Segundo Heidegger (2015), é no "passatempo" que põe sua essência, revelando a relação e o modo como nos movemos nele. Movidos pelo tédio, sempre buscamos uma ocupação no mero passatempo, mas não interessa as formas dessa ocupação, se é útil ou não, se beneficia ou não, muito menos os resultados dela. Interessa-nos apenas "estar-ocupado" e somente isto - procurando "qualquer estar-ocupado". Por que isto? Somente para nos livrar da serenidade do tédio que começa, silenciosamente, a emergir o vazio. Porém, a lida com certas coisas é provisória, depois ela nos abandona não nos requisitando mais, e ficamos apreensivos diante da falta de solicitação do ser.

Procuramos, assim, os mais diversos afazeres para fuga, principalmente na imersão nos entretenimentos e divertimentos desenfreados, como bem explicitou o filósofo Pascal (1973) em seu livro "Pensamentos", no qual empregou para divertimento a palavra di-vertere: "se afastar de". Nesse sentido, o divertimento é aquilo que faz com que nos distraiamos para passarmos ao largo do tédio, "divergindo" de tal situação e procurando outra na qual o homem não possa mais pensar em seu nada. $\mathrm{O}$ mais importante é que este [di-vertere] não trata-se só das distrações como os jogos, mas inclui também as atividades laborais, as pesquisas científicas, todas elas são formas de ofuscar o vazio. O pensador diz que:

Nada é mais insuportável para ao homem do que ficar em absoluto repouso, sem paixões, sem negócios, sem divertimento, sem aplicação. Sente então sua inanidade, seu abandono, sua insuficiência, sua dependência, sua impotência, seu vazio. Imediatamente surgirão no fundo de sua alma o tédio, o negrume, a tristeza, o pesar, a irritação, o desespero (PASCAL, 


$$
\text { 1973, p. 53). }
$$

A característica que se assemelha a esse estado é o "tédio-profundo", uma grande indiferença ante o mundo que eclode justamente por um sofrimento advindo do esvaziamento, ficando, assim, desamparado pela paragem do tempo. Assim, o cansaço tedioso do presente anula as experiências ekstáticas temporais do passado e do futuro, envolvido em um presente inerte, onde não se espera nada - uma espécie de anulação do desejo. O desassossego faz, então, desaparecer o movimento, e a impossibilidade de se tornar outro se instala fortemente como um "eu" petrificado (PASCAL, 1973)

Essa disposição é tematizada fortemente por Pessoa (1999) no "Livro do desassossego", onde concebe no tédio a disposição fundamental do século XX, uma inércia esmagadora em que o peso do aborrecimento do nada, contido na experiência, chega ao esvaziamento dos gestos, impossibilitando a ação. Essa moléstia da 'alma' é uma espécie de cansaço interminável que penetra de tal maneira na nossa presença ao ponto de paralisamos. "Não é o tédio a doença do aborrecimento de nada ter que fazer, mas a doença maior de sentir que não vale a pena fazer nada. Sendo assim, quanto mais há que fazer, mais tédio há que sentir" (PESSOA, 1999, p. 392). O poeta completa seu pensamento afirmando:
O meu tédio assume aspectos de horror; o meu aborrecimento é um medo. O meu suor não é frio, mas é fria a minha consciência do meu suor. Não há mal estar físico, salvo que o malestar da alma é tão grande que passa pelos poros do corpo e o inunda a ele também. É tão magno o tédio, tão soberano o horror de estar vivo, que não concebo que coisa haja que pudesse servir de lenitivo, de antídoto, de bálsamo ou esquecimento para ele (PESSOA, 1999, p. 194).

Essa descrição mostra a magnitude da compreensão que Heidegger (2015) interpretou sobre a afinação do tédioprofundo, a que comumente chamamos hoje de depressão. É uma espécie de saudação morta, onde a vivacidade contida na nossa correspondência se esvai completamente, manifestando a inércia, o vácuo, a frieza de um nada mortífero que impossibilita buscar uma porta de saída. Dito de outra forma, na depressão acontece uma perca da esperança total, isto é, toda substância morre e, assim, nosso ser recobre-se de uma desolação, um desterro - a alma naufraga no mar da fria noite da indigência.

A vacuidade contida no estado depressivo é uma espécie de amolecimento do tônus (tonalidade), de tal forma que as sensações que se pas- 
sam no ser do ser humano, são de uma completa nadidade. Trata-se de um procurar sem encontrar-se, de um "não-lugar" ao infinito, de um "estar estagnado" em meio às relações cotidianas. Nesse caso o existente se mostra expulso da sua própria morada, no tédio profundo (depressão), justamente por desaparecer nossa esperança, prolongando-se indefinidamente ao pálido esgotamento dos sentidos que a tonalidade afetiva atravessa. "Vejo casas inexpressivas, caras inexpressivas, gestos inexpressivos, pedras, corpos, ideias - está tudo morto" (PESSOA, 1999, p. 203).

No livro "Nos cumes do desespero", o filósofo Cioran (2011) retrata bem, no aforismo "melancolia", sobre essa questão da correspondência envolvida em todos esses estados e sua íntima ligação com todo o ambiente em geral, que põe a cada vez sintonias atmosféricas diversas, de acordo com a ressonância de cada presença. Segundo o pensador, é como se aquilo que vemos no "exterior" fosse uma tortura interior, enfatizando que todo nosso olhar está perpassado primordialmente pelo "ser-afinado" da tonalidade. Seu étimo em latim, advindo do grego: melankholia, significa bílis negra, uma tristeza vaga, um abatimento do tônus. Isso faz com que para onde olhemos a afinação nos acompanhe, basta olhar alguém com uma melancolia intensa para percebermos sua tensão espiritual.

Por que esse olhar infinito nos acom- panha, estando fora de nós? Ora, esse olhar afinado acontece de duas maneiras, segundo Cioran (2011): a "positiva", manifestada pelo entusiasmo, ou seja, uma intensidade capaz de quebrar barreiras para alargar os horizontes, que rompem as determinações habituais sempre no intuito de se expandir; e no modo "negativo", quando o olhar afinado dilata um vazio extremo. Como assim? A plenitude sede lugar para dentro de um vazio de margens indefiníveis em toda profundeza do ser - uma diminuição do tônus, um "retorno ao não-ser".

Vez por outra, sentimos esses estados se abaterem sobre nós e ficamos de frente ou na proximidade do nada, em uma espécie de cansaço interminável presente na melancolia, depressão, tédio profundo - que nos separa de todas as coisas. Como isso acontece? O ritmo da vida modifica a tal ponto de permanecemos à margem dos acontecimentos normativos, perdendo o elo com a vida - ficando indiferente. Mas, ao mesmo tempo, permite-nos a diferenciação do homem do mundo, pois o mundo fica de frente ao homem em sua inocência, ou seja, se mostra desnudado das significações cotidianas. Como diz Cioran (2011, p. 29):

O cansaço separa o homem do mundo e de todas as coisas. O ritmo intenso da vida diminui, as pulsações orgânicas e a atividade interior perdem essa 
tensão que particulariza a vida no mundo e que são momentos imanentes à existência.

A intimidade com o mundo desaparece e a vida fica frágil e problemática pela sensação de vagueza do mundo, que fica com outro invólucro e o distanciamento de tudo que é notável. O "estado melancólico" tem sempre a característica de uma expansão do vazio em direção aos cumes, por estar além do mundo habitual. O ser-homem passa a mergulhar na reflexão sobre a negatividade que é a sua, ganhando asas para voar em direção contrária da plenitude entusiástica, isto é: para a solidão em sentido ilimitada. Ademais, "a melancolia comporta um estado vago, sem qualquer intenção determinada" (CIORAN, 2011, p. 30).

De acordo com Heidegger (2015), ao se distanciar da existência e estar abandonado a si na melancolia, o ser humano fica vago, deixado só no mundo. Ademais, quanto mais consciência tem dessa ilimitada infinidade de seu olhar no mundo pela afinação, mais aguda fica a compreensão de sua própria "finitude" (o chamado beijo da existência, para sua dança indeterminada). Nos estados melancólicos, deixa de ser torturante e se transveste de uma beleza estranha, sendo suspenso da vida em seu isolamento, que manifesta um modo de ser onde viver significa não mais participar da vida. O solitário se isola sem esperar mais nada, em um caráter estético. Uma afinação suave acontece pela passividade contemplativa de uma serena tranquilidade da alma, em que as problemáticas do dia a dia se reduzem ao silêncio.

Acoplado a isso, há uma renovação que faz com que diminua ou aumente esse vazio a partir da tonalidade, como o "pesar", um sentimento profundo que exprime sobre a parte morta em nós. Cioran (2011) enfatiza de forma direta, concomitante com o pensamento heideggeriano, que mesmo a melancolia mais sombria é uma afinação temporária e não uma doença constitutiva no corpo do homem, como uma coisa inata. Porém, as distinções e diferenciações dos graus desses estados só podem ser percebidos e evidenciados pela tonalidade da visão, ou seja, a partir do modo como o "ser-afinado" se relaciona com a sua ilimitada visão, variando e oscilando de acordo com os indivíduos, e as respectivas situações. Para Cioran:
A renovação de certos eventos ou tendências anteriores, a adi- ção à nossa atual afetividade das sensações e do meio em que estas nasceram para deixá- lo em seguida - tudo isso é es- sencialmente determinado pela melancolia (2011, p. 31).

A unanimidade entre todos os pensadores aqui citados possibilitou esse diálogo sobre o desassossego contemporâneo em relação ao caráter inde- 
terminado da afinação atmosférica que acomete o ser-aí humano em sua abissalidade. Desse diálogo entendemos que algumas atmosferas acontecem em meio ao predomínio intramundano, presente na cotidianidade com sua tranquilidade e segurança; outras vezes ocorre pela falta das referências significativas, onde os entes se afastam, não mais nos solicitando, deixando-nos vazios, no "não-ser". Mas, em meio a estes desassossegos e crises existenciais, onde iremos encontrar sossego autêntico? Será que ele existe? Essa experiência só poderá acontecer quando houver o despertar do ser-aí (Dasein) e quando gozarmos o momento presente em sua singularidade, através da plenitude temporal retida, isto é, um tempo que mostra profundidade e perspectiva, entregando-se a todo o acontecimento em sua autenticidade naquilo que é. Transfigurando sua própria experiência de ser, ou talvez na superação do "homem", isto é, da condição humana de ser homem para o estágio de "super-homem" ou "além-homem", como sugeriu Nietzsche (2011) em sua obra, "Assim falou Zaratustra".

\section{Considerações Finais}

A compreensão hermenêutico-fenomenológica sobre a interpretação das crises existenciais contemporâneas e suas formas de proceder, possibilitaram olhar mais uma vez para aquilo que sempre perfaz nossa lida relacional nas experiências fáticas, manifestadas de início e na maioria das vezes na ocupação cotidiana. Somente com esse olhar podemos chegar à proximidade da temporalidade que nos permeia, como também às inquietudes e sofrimentos em que o ser-aí (Dasein) manifesta-se. Por ser primordialmente um ser-no-mundo, acompanha o curso do rio histórico e com isto se afeta, pois se correlaciona com modos de ser doentios e, assim, definha.

A analítica aqui realizada ateve-se aos principais fenômenos vigentes de nossa época "desassossegada" no intuito de buscar uma melhor apropriação em contraposição ao pensamento paradigmático do corpo-biológico decorrente da neurociência, onde o ser humano é visto como uma conexão químico-física. Foi visto na descrição dos diferentes modos existenciais da nossa temporalidade que o ser humano está inserido e, portanto, tocado afetivamente pela relação de sentido e falta de sentido em que está imerso.

Observamos que nenhum neurônio pode dar conta da "relação-com" e da "compreensão" que temos dessa relação, nem muito menos do "tempo" que proporciona os nossos modos de ser, bem como das afinações existenciais das tonalidades afetivas. A cegueira acontece quando tomamos emprestada a visão mecanicista biológica como absoluta e não a questionamos, entregando-nos sem pensar e imedia- 
tamente aos especialistas e aos psicofármacos: medicamentando biologicamente às vezes algo não biológico.

A partir do diálogo dos pensadores citados, abriu-se, pois, uma chave de acesso para a pensabilidade de interpretação dos fenômenos ditos "psicopatológicos" contemporâneos, através das tonalidades afetivas fundamentais tanto para uma prática clínica psicológica quanto para uma apropriação pessoal sobre os momentos constitutivos que nos afetam.

A relevância de realizar um estudo com esse perfil está em apreender sem- pre novas linguagens. Afinal a existência humana é um labirinto abissal, um mistério difícil de desvelar, e não pode ser acabada por nenhum esforço metodológico. Isso implica dizer que toda objetividade é uma delimitação, ou melhor, uma simplificação do ser do ente que somos nós. Mas, o caminho está aberto... com muito chão ainda para percorrer. Nessa aventura, eis a grande tarefa: analisarmos o ente que somos nós mesmos a cada vez e a própria temporalidade onde nos encontramos e na qual nos perfazem.

\section{Referências}

ASSIS, Machado de. Várias histórias. Série Bom Livro. 4. ed. São Paulo: Editora Ática, 2001.

BORGES-DUARTE, Irene. Sossego e desassossego: o paradoxo do tempo vivido. In: DUTRA, Elza [org.]. O desassossego humano na contemporaneidade. Textos apresentados III Congresso Brasileiro de Psicologia \& fenomenologia. 1. ed. Rio de Janeiro: Via Verita, 2018.

CASANOVA, M. A. Eternidade frágil: ensaio de temporalidade na arte. 1. ed. Rio de Janeiro; Via Verita, 2013.

CASANOVA, M. A. Mundo e historicidade: leituras fenomenológicas de ser e tempo: vol. 1: existência e mundaneidade. 1. ed. Rio de Janeiro; Via Verita, 2017.

CIORAN, Emil. Nos cumes do desespero. Disponível em: [http://lelivros.love/book/baixar-livro-nos-cumes-do-desesperoemil-cioran-em-pdf-mobi-ou-ler-online/]: acesso em [25/ 10/ 2019].

HAN, Byung-Chul Han. Sociedade do cansaço. Tradução de Enio Paulo Giachini. 2. ed. ampliada. Petrópolis, RJ: Vozes, 2017.

HEIDEGGER, Martin. Conceitos fundamentais da metafísica: mundo, finitude, solidão. Tradução de Marco Antônio Casanova. 2. ed. Rio de Janeiro: Forense Universitária, 2015.

HEIDEGGER, Martin. El concepto de tiempo. Trad. Jesus Adrián Escudeiro. Barcelona: Herder Editorial, S. L, 2008.

HEIDEGGER, Martin. Seminários de Zollikon: protocolos, diálogos, cartas; editado por Medard Boss; tradução: Gabriela Arnhold, Maria de Fátima de Almeida Prado; revisão da tradução: Maria de Fátima de A. Prado e Renato Kirchner. 3. ed. rev. - São Paulo: Escuta, 2017.

HEIDEGGER, Martin. Ser e tempo; Tradução revisada e apresentação de Marcia Sá Cavalcanti Schuback; posfácio de Emanuel Carneiro Leão. 10. ed. Petrópolis, RJ: Vozes; Bragança paulista, SP: editora Universitária São Francisco, 2015.

HUSSERL, Edmund. Investigações lógicas: prolegômenos à lógica pura. Volume 1. Tradução Diogo Ferrer. 1. ed. Rio de Janeiro, 2014.

NIETZSCHE, Friedrich Wilhelm. A gaia ciência. Tradução Paulo Cézar de Souza. 1. ed. - São Paulo: companhia das letras, 2012.

NIETZSCHE, Friedrich Wilhelm. Assim falou Zaratustra: um livro para todos e para ninguém. Tradução, notas e posfácio Paulo Cézar de Souza. São Paulo: Companhia das Letras, 2011.

NIETZSCHE, Friedrich Wilhelm. Humano demasiado humano: um livro para espíritos livres. Tradução, notas e posfácio Paulo Cézar de Souza. São Paulo: Companhia das Letras, 2005. 
PASCAL, Blaise. Pensamentos. Tradução de Leonel Vallandro. Porto Alegre: Editora Globo; Brasília, INL, 1973.

PESSOA, Fernando. Livro do desassossego. Composto por Bernardo Soares, ajudante de guarda-livros na cidade de Lisboa; organização Richard Zenith. São Paulo: Companhia das Letras, 1999.

SÁ, Roberto Novaes de. Para além da técnica: ensaios fenomenológicos sobre psicoterapia atenção e cuidado. 1. ed. Via Verita. Rio de Janeiro: 2017.

Recebido / Received: 03/10/2019

Aprovado / Approved: 27/01/2020

Publicado / Published: 30/07/2020 
